\title{
SIMULATION OF THE COMBUSTION PROCESS IN THE ELECTRONICALLY CONTROLLED MARINE DIESEL ENGINE
}

\author{
Stefan Kluj \\ Gdynia Maritime University, Engineering Department \\ Morska Street 81-87, 81-225 Gdynia, Poland \\ tel.:+4858 6901439, fax: +48586901399 \\ e-mail:kluj@wm.am.gdynia.pl
}

\begin{abstract}
The introduction of the electronically controlled low-speed diesel engines has raised a number of new problems caused mainly by the influence of these electronic system settings on the combustion process. The wide set of the combustion press settings is now available for the chief engineers on the board of the ship and for the shipyard experts during the sea trials. This opens many new possibilities for the combustion process optimization but also causes the danger of the serious engine malfunction due to the improper settings.

The paper presents the mathematical model of the electronically controlled low-speed marine diesel engine ant the special attention is paid to the available settings of the combustion process. The effective compression ratio, the injection timing and the exhaust valve setting can be adjusted in a similar manner like in the actual engine. The combustion pressure curves, the mean indicated pressure, the exhaust gas temperature can be observed when changing the combustion settings.

The paper describes in detail the results of the several most typical simulations like change of the given combustion pressure increase, the change of the effective compression ratio, the change of the exhaust valve opening timing and the change of the maximum load setting.
\end{abstract}

Keywords: marine diesel engines, simulation, combustion engines, electronically controlled engines

\section{Introduction}

The introduction of the electronically controlled low-speed diesel engines has raised a number of new problems - caused mainly by the influence of these electronic system settings on the dayto-day engine operation. These days, the engineer can expect not only basic operations i.e. the engine starting, stopping or load change, but also they can easily change the injection timing, compression ratio, exhaust gas temperature, or load balance of the engines. Moreover, many of all these essential operator functions have to be simulated within the modern simulator. This makes it difficult for the software developer to establish the boundaries between the operational functionality and the key maintenance tasks. On the other side of the equation, the engine manufacturer could update the engine control system software version, its function, and the way the engine is operated, so we continually consider how these electronic controls should be implemented into the engine room simulator themselves.

One could think that the operation of the electronically controlled engines should be easier than a conventional one, because of the high automation level. This is not supported in reality, mostly because the operation of a modern engine (even if planned as a simple one) is very different from the operation of the classic engine [7]. Despite the differences between the construction and operation of the conventional engines, their operation is quite similar i.e. the actions taken in order to start, stop, or load the engines - even if the actual control element is different.

Indeed, there are several important differences between the operation of the conventional and electronically controlled low-speed engine. All of these functions have been implemented into Virtual Engine Room 6 (VER6) simulator with a special attention paid to the simulation of the combustion process in the electronically controlled marine low-speed engine. 


\section{Mathematical model}

The mathematical model of the combustion process in VER6 simulator has been based on the well-proven mathematical model of the Turbo Diesel simulator $[6,8]$. The great care has been paid to the mathematical modelling of the fuel injection and the combustion process [4]. In general, the technique is to solve the governing equations of state and of conservation of energy and mass on a step-by-step basis, using small crank angle increments (2 degrees) [1]. The calculation sequence invariably divides itself into two major portions, for closed and open period, starting with assumed trapped conditions of the cylinder charge at the beginning of compression. The stable values of these conditions are obtained only after several successive cycles have been evaluated.

The airflow rate through a turbocharged diesel engine has been simulated as a function of the engine speed, compressor delivery air density and the pressure difference between intake and manifolds during the period of a valve overlap. The digitized turbocharger characteristic has been used in order to simulate its operation. Making suitable simplifying assumptions concerning the diesel cycle, as well as for a compressor and turbine efficiency, it is possible to construct curves of specific power for engine, compressor and turbine as a function of a boost pressure. Such a mathematical modelling, based on the details of the diesel engine and the compressor map, has made possible the determination of the operating points for both an engine and a turbocharger.

Special attention has been paid to the digital simulation of an exhaust gas emission including the concentration of $\mathrm{CO}_{2}, \mathrm{SO}_{2}$ and $\mathrm{NO}_{\mathrm{x}}[3,4,8,10]$. The mathematical model was validated during the tests at Sulzer A25 diesel engine in the laboratory, but the final model has been adapted to the actual parameters of the low speed diesel engine. This model created for the low speed diesel engine MAN 7S70-ME has been based on the technical data published by the engine producer but also on the original test results collected during the sea trials of the two last car-carrier ships produced in Gdynia Shipyard in which the author has attended.

\section{Simulation results}

Because of the requested compatibility with original ME type low speed engine, the several below listed simulations have been added.

- The change of the exhaust valve opening angle in each cylinder $\left(-2-+1{ }^{\circ} \mathrm{Crank}\right.$ Angle $)$,

- The change of the maximum combustion pressure in each cylinder $(-20-+20$ bar $)$,

- The change of the compression ratio in each cylinder(-2 - +2),

- The change of the maximum load limit in each cylinder $(80-100 \%)$,

- The change of the high load offset in each cylinder $(-10-+10 \%)$,

- The change of the low load offset in each cylinder $(-6-+6 \%)$,

- The switching between the economy and emission (low NOx) operating mode.

\section{Change of the exhaust valve-opening angle}

The change of the exhaust valve-opening angle influences the temperature of the exhaust gases mainly (see Fig. 1). This setting can be used by the engine room crew in order to compensate the influence of the delayed combustion caused by the improper fuel nozzle operation for example. Of course, such an action will not remove the cause of the problem, but can temporarily protect the exhaust valve seat against overheating.

\subsection{Change of the maximum combustion pressure}

The VIT device responsible for the change of the injection timing in the camshaft-controlled engines has been replaced by the electronically controlled continuous change of the commencement of fuel delivery in ME engines. Additionally, the chief engineer has the possibility to change it for individual cylinders what seems to be a useful feature in the practical engine operation. Surprisingly enough, this feature has been named "maximum cylinder pressure offset" (see Fig. 2). 


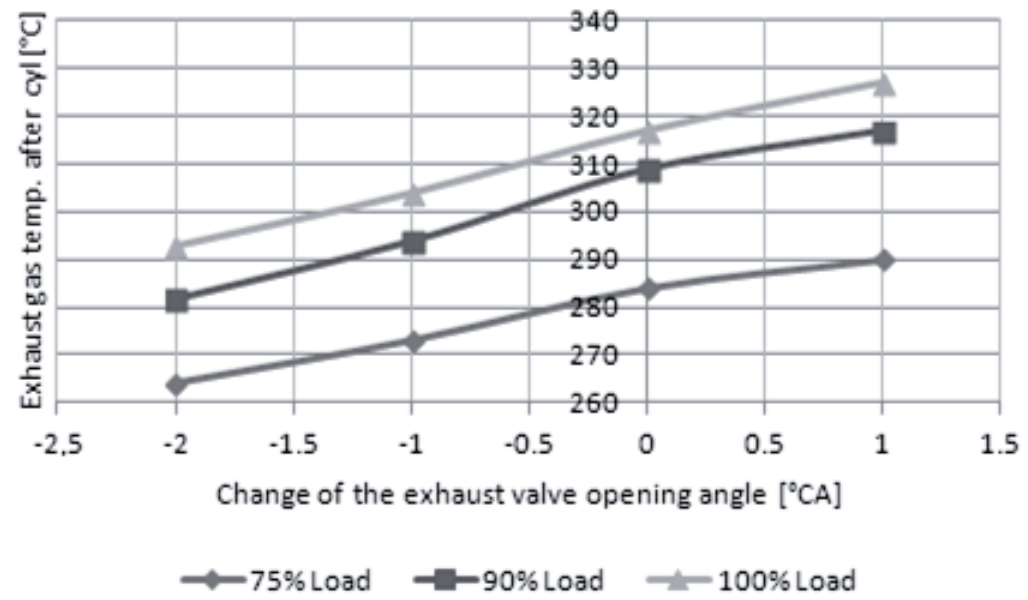

Fig. 1. The influence of the exhaust valve-opening angle on the exhaust gas temperature

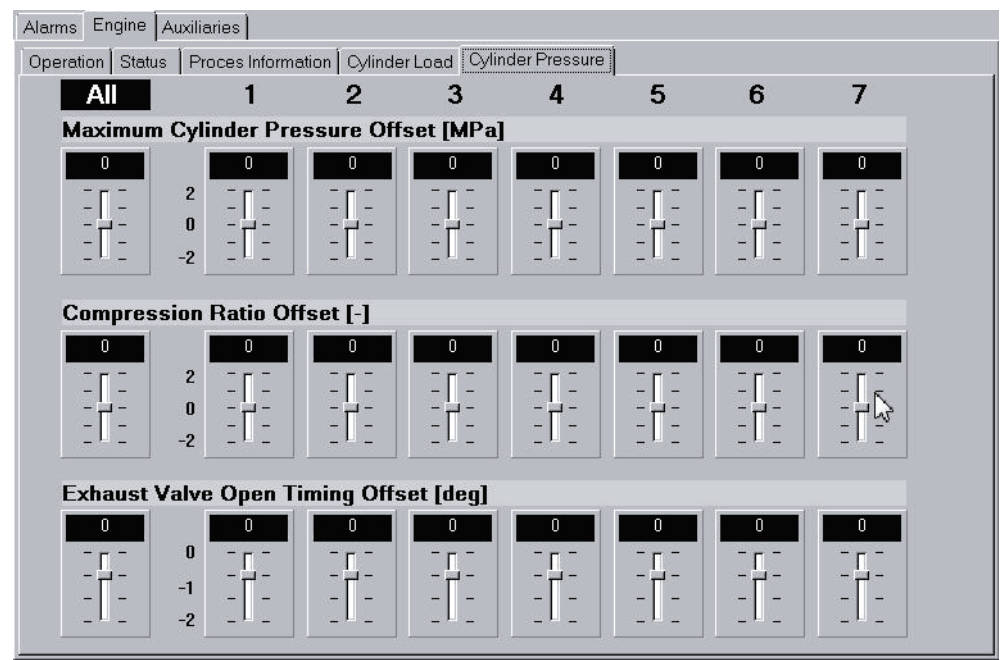

Fig. 2. The VER6 simulator screen showing the sliders for the cylinder setting change

The possible application of this future may be compensation of the fuel pump wear (being a part of the Hydraulic Cylinder Unit - HCU) or the excessive delays in the control valve operation (ELFI). The example of the cylinder pressure change caused by the maximum pressure setting has been shown at Fig. 3.

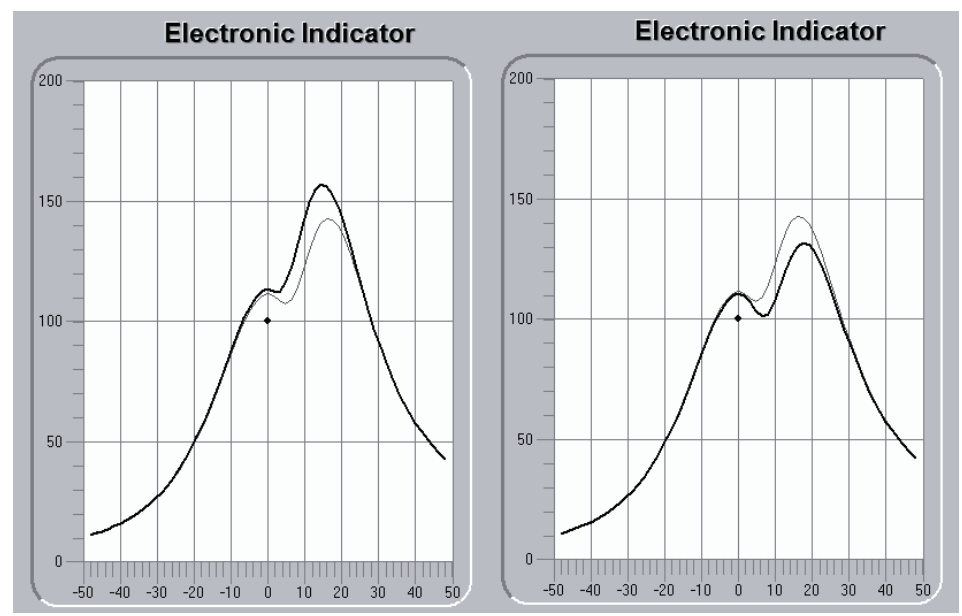

Fig. 3. The change of the combustion curve caused by increasing the maximum pressure (+20 bar left) and by decreasing it (-20 bar right). Blue line - the actual pressure in the tested cylinder, green line the reference pressure 


\subsection{Change of the compression ratio}

The term "compression ratio" CR (1) used in the original ME software is slightly different than this used traditionally in the theory of diesel engines [1] and means the actually pressure ratio PR (2). Practically, the requested change of PR is achieved by the change of the exhaust valve-closing angle, so the term "compression ratio change" will be used in this paper.

$$
C R_{\text {eff }}=\frac{V_{1 \text { eff }}}{V_{2}}
$$

where:

$\mathrm{CR}_{\text {eff }}$ - effective compression ratio [-],

$\mathrm{V}_{1 \text { eff }}$ - volume of the cylinder when exhaust valve closes $\left[\mathrm{m}^{3}\right]$,

$\mathrm{V}_{2}$ - volume of the cylinder in TDC $\left[\mathrm{m}^{3}\right]$.

$$
P R=\frac{p_{2}}{p_{1}}
$$

where:

PR - compression coefficient [-],

$\mathrm{p}_{2}$ - compression pressure [bar],

$\mathrm{p}_{1}$ - pressure in cylinder at the beginning of compression [bar].

The compression ratio (and the pressure ratio as well) increases when exhaust valve closes earlier, so it can be used in order to compensate the effect of the worn of piston rings or an untight combustion chamber (Fig. 4). The danger is that this method can be used by the engineering crew instead the necessary maintenance what can lead to serious faults like piston seizures or cylinder head sealing burnouts. On the other hand, the lower compression ratio increases the exhaust gas temperature (Fig. 5) and decreases the cycle efficiency.

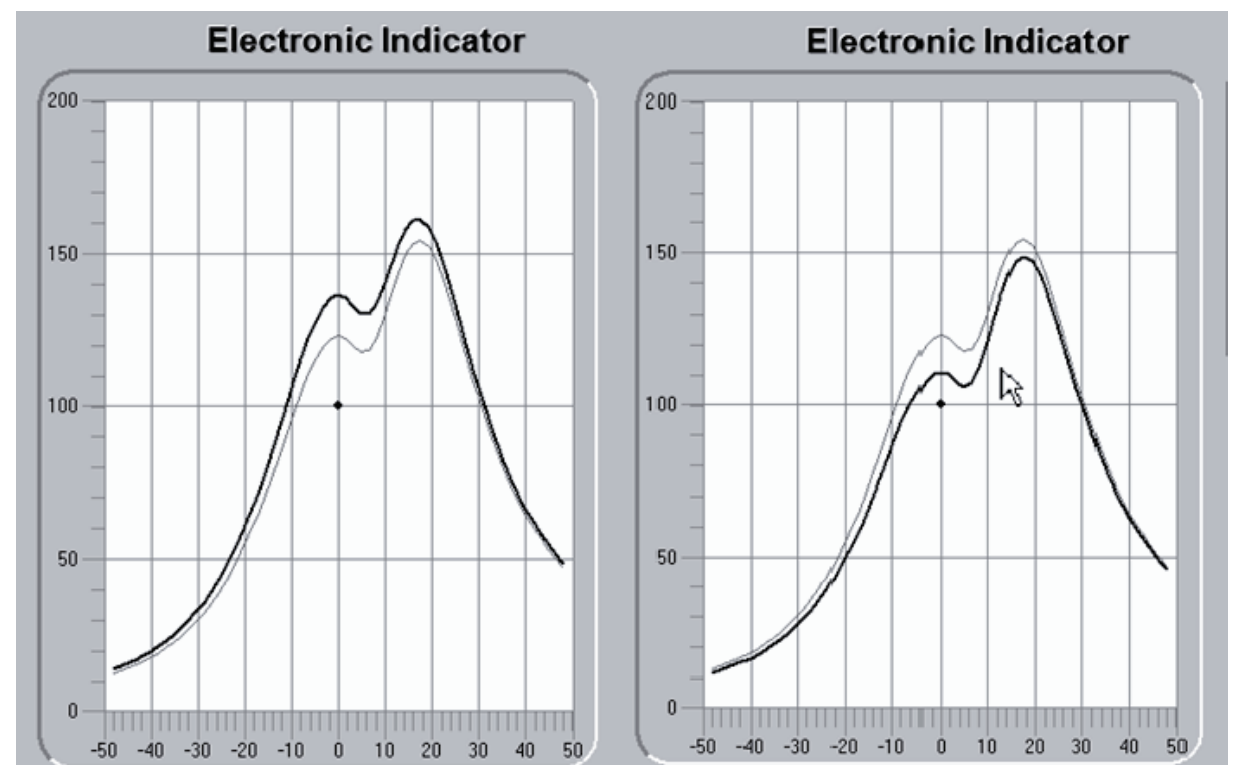

Fig. 4. The change of the combustion curve caused by increasing the compression ratio (left) and by decreasing it (right). Blue line - the actual pressure in the tested cylinder, green line - the reference pressure

\subsection{Change of cylinder load}

The simulation of the engine load limitation (total maximum load, cylinder load at low engine load and cylinder load at high engine load - see Fig. 6) is rather simple and is simulated as an earlier fuel injection cut-off. Please observe that the compression pressure in the corresponding cylinder is slightly lower because of the combustion chamber lower temperature. The practical 
application of this setting in the actual engine operation can be quite important, especially when running-in a cylinder after the piston ring repair or a cylinder liner exchange.

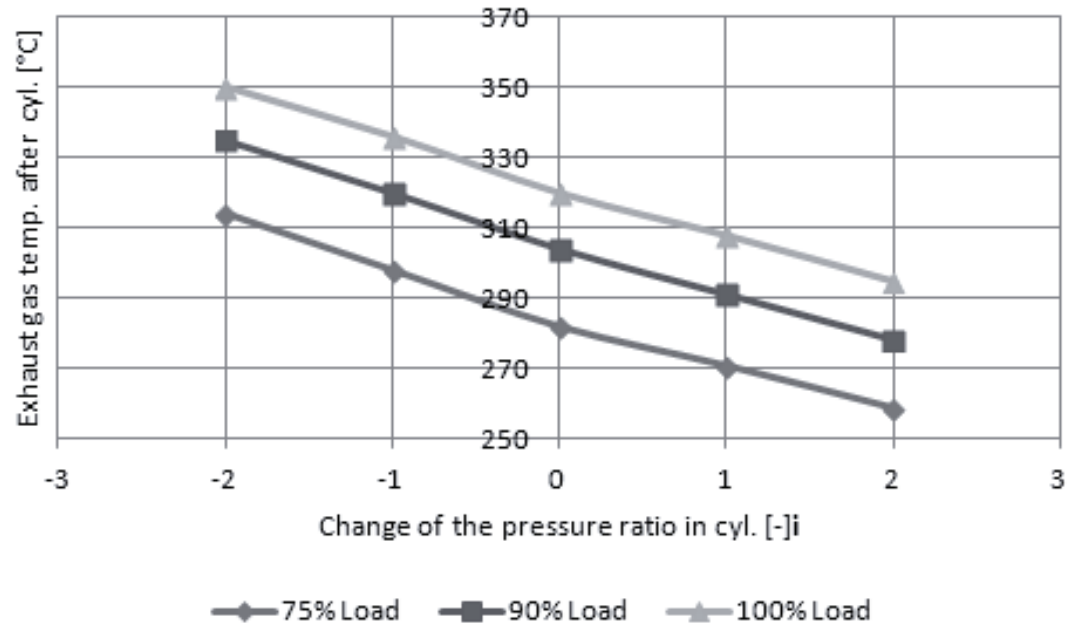

Fig. 5. The influence of pressure ratio change on the exhaust gas temperature

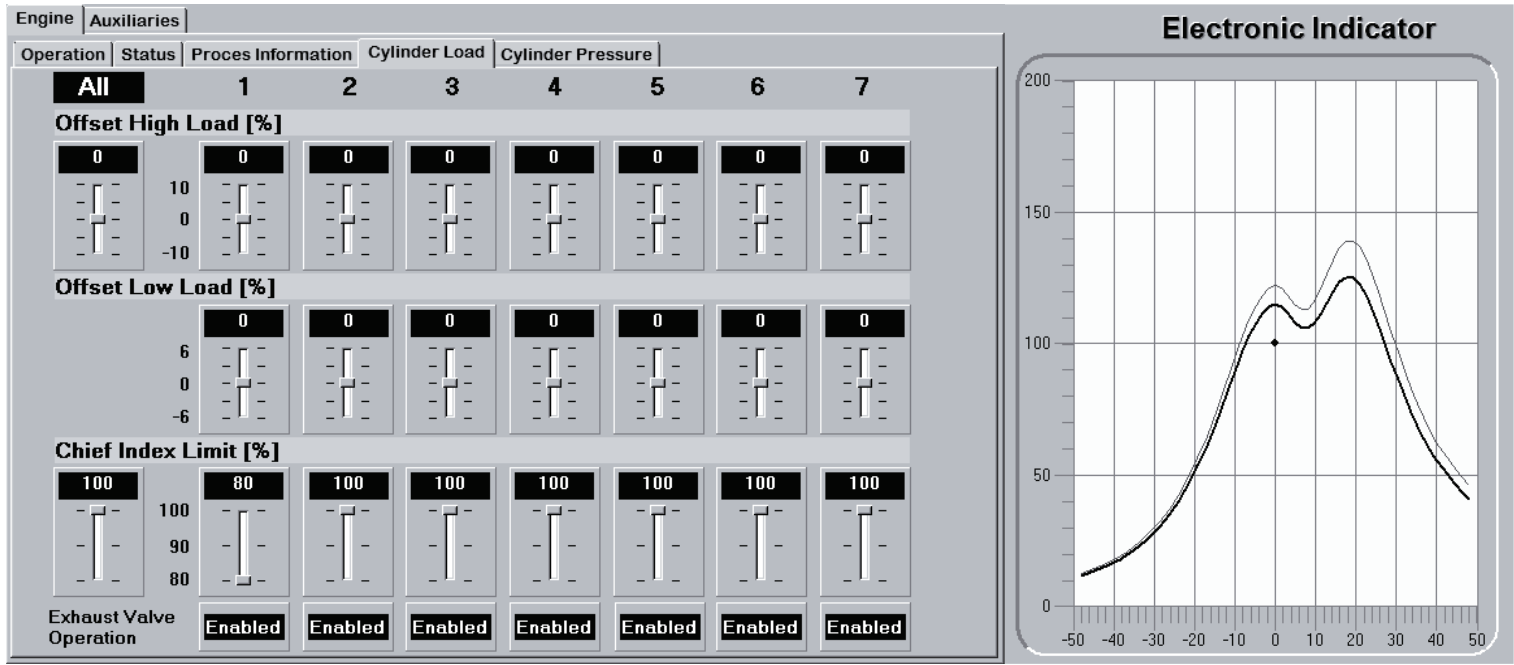

Fig. 6. The VER6 simulator screen showing the sliders for the cylinder load setting change (left) and the corresponding combustion curve (right)

\subsection{Switching between the economy and emission operating mode}

The research has shown that the most challenging and most difficult task is the modelling of the $\mathrm{NO}_{\mathrm{x}}$ emission when switching between economy (low fuel consumption) and emission (low $\mathrm{NO}_{\mathrm{x}}$ ) operating mode [5]. The main reason of this problem was the lack of the possibility to conduct an active experiment on the actual low speed engine on one hand, and the lack of the detailed exhaust gas analysis in both modes.

As it has been mentioned above that attempt to adapt, the well-tested and validated emission model from the four-stroke medium speed diesel for the low speed diesel engine was not as quite successful as expected. Fig. 7 shows the relative $\mathrm{NO}_{\mathrm{x}}$ emission as a function of an engine load where both calculated and test bed results (published by the engine manufacturer [2]) have been compared. It can be seen that the current emission model requires further improvement because its accuracy is not satisfactory.

\section{Conclusion}

The main advantage of the electronically controlled engine is the possibility to adjust on fly a number of injections, lubrication and exhaust valve settings. 


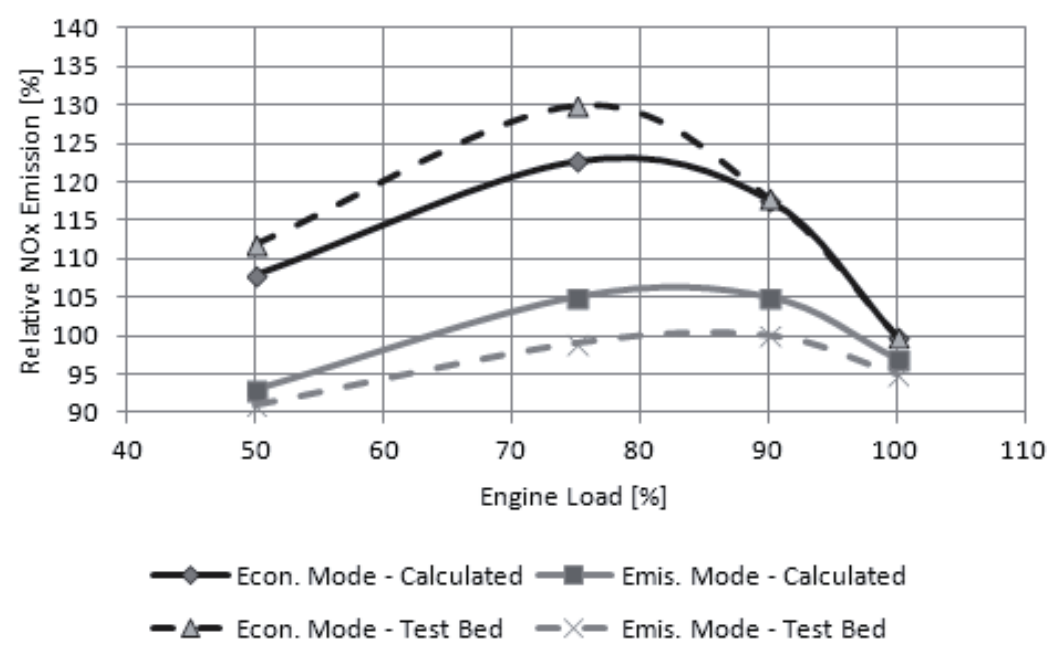

Fig. 7. The relative changes of NOx Emission as a function of engine load (test bed results from [2])

This makes the control panel itself a powerful tool, but also it is a danger to the untrained crew. For instance, some engineers may wish to compensate the effect of worn piston rings and lowered compression pressure by a simple adjustment of the compression ratio slider. This action removes the symptoms but not necessarily the cause of the problem.

Similarly, when there is increased exhaust gas temperature caused by a poor atomization of an injector, it can be easily solved by a delayed opening of the exhaust valve. Because of this type of example, simulator training is especially useful, not only for the training of ab-initio cadets, but also for the education continuation of experienced engineers who have only just started to work with electronically controlled engines. The trainee can then try different settings (for example the change of the injection advance) using the simulator, and they can observe their influence on the combustion before using these skill for the actual engine type.

\section{References}

[1] Challen, B., Baranescu, R., Diesel Engine Reference Book, Elsevier, Oxford 2003.

[2] Collective work, ME Engines - the New Generation of Diesel Engines, MAN website http://www.mandiesel.com/files/news/filesof2810/p412-0503.pdf status, 24.05.2014.

[3] Genesis Engineering Inc. \& Levelton Engineering Ltd., Non-road Diesel Emission Reduction Study, prepared for Puget Sound Clean Air Agency, Oregon Department of Environmental Quality and U.S. Environmental Protection Agency 2003.

[4] Habib, M. A., Elshafei, M., Dajani, M., Influence of Combustion Parameters on $N O_{x}$ Production in an Industrial Boiler, Elsevier, Oxford 2007.

[5] International Convention for the Prevention of Pollution from Ships (MARPOL) Annexes IVI, International Maritime Organization, London 2011.

[6] Kluj, S., Symulowanie wybranych niesprawności na symulatorze Turbo Diesel 4, Zeszyty Naukowe Akademii Morskiej w Gdyni, Vol. 60, 2009.

[7] Kluj, S., Simulating Electronically-Controlled Diesel Engines, MER - Marine Engineers Review, 2010.

[8] Kluj, S., Turbo Diesel 5 - The New Simulator for Maritime Engineering Training, Journal of CIMAC, Vol. 7, No. 2, 2012.

[9] Sobieszczański, M., Model otwartego wykresu indykatorowego ciśnień w komorze spalania silnika wysokoprężnego, Silniki spalinowe, $\mathrm{Nr}$ 4, 1972.

[10] Westlund, A., Simplified Models for Emission Formation in Diesel Engines During Transient Operation, Doctoral thesis, Department of Machine Design, Royal institute of Technology, Stockholm 2011. 